\title{
SENAME ¿Protección o punición? Comentarios de su acción biopolítica y disciplinatoria
}

\section{SENAME. Protection or punishment? Coments about its biopolitical and disciplinatory action}

\author{
Felipe Ramírez Hinrichsen ${ }^{1}$ \\ Universidad Santo Tomás, Chile
}

(Recepción: Octubre 2009 - Aceptación: Diciembre 2009)

\begin{abstract}
Resumen
Este artículo problematiza sobre las implicaciones biopolíticas y disciplinatorias de las líneas de acción de SENAME, propuestas para el período 2006-2010, respecto de la población infantil y adolescente. Abordando los conceptos de Infancia y Vida Desnuda del filósofo Giorgio Agamben, la función de la pericia psicológica desde Michel Foucault, y realizando una breve referencia histórica-arqueológica desde Gabriel Salazar, se reflexiona sobre la operación de captura subjetiva de niños y adolescentes vulnerados y potencialmente peligrosos. Con ello se cuestiona la aporía de un enfoque de protección de derechos que sin embargo lleva consigo un control social de la desviación normativa.
\end{abstract}

Palabras clave: Biopolítica, SENAME, Infancia, Vida desnuda, Control social.

\begin{abstract}
This article problematizes the biopolitics and disciplinaries implications of the action guidelines of SENAME, proposed for the period 2006-2010, about children and adolescents. Addressing the concepts Infancy and Bare Life of the philosopher Giorgio Agamben, the role of psychological expertise from Michel Foucault, and giving a short historical-archaeological reference from Gabriel Salazar, it is reflected the subjective capture operation of children and adolescents violated and potentially dangerous. Is questioned the aporia of a rights protection approach that nevertheless carries a social control of the normative desviation.
\end{abstract}

Key Words: Biopolitics, SENAME, Infancy, Bare life, Social control. 
Señores dénme permiso

pa' decirles que no creo

lo que dicen las noticias

lo que cuentan en los diarios

lo que entiendo por miseria

lo que digo por justicia

lo que entiendo por cantante

lo que digo a cada instante

lo que dejo en el pasado

las historias que he contado

o algún odio arrepentido

El viaje, Schwenke y Nilo

\section{Introducción}

El presente artículo tiene como objetivo problematizar algunas de las implicancias ideológicas, institucionales y prácticas que el Servicio Nacional de Menores (SENAME) sostiene sobre la protección de los derechos de infancia, a propósito de sus efectos disciplinatorios y acción biopolítica. Con ello pretendo profundizar en la aporía y la articulación entre dos grandes instituciones: la Convención de los derechos de la Infancia y el aparato jurídico del Estado chileno. Dichas instituciones se despliegan como dispositivos de control y subjetivación a modo de exclusión incluyente, integrando en sus políticas pero a la vez con ello excluyendo a la población infanto-juvenil peligrosamente vulnerable de los estratos socioeconómicos menos favorecidos. Para ello haré referencia al Marco General de SENAME (s/ año) dispuesto para el período 2006-2010, donde éste expresa sus líneas doctrinarias y el enfoque propuesto respecto de la infancia y adolescencia en relación a dos grandes áreas de acción, lo proteccional y lo infraccional.

Antes de comenzar este recorrido se me hace necesario, primero, señalar qué es lo que he de entender por infancia, o desde qué punto enfocaré este campo, que es a la vez el objeto de y ente convocante a la ocasión de esta máquina de control en la producción de subjetividades.

\section{La Infancia: no-lugar trascendental a la tópica de lenguaje y la racionalidad.}

Hoy en día se ha hecho un lugar común que hablar de infancia es hacer referencia a la niñez en su sentido cronológico, es decir, como una edad del desarrollo por la cual atraviesa todo ser humano a lo largo de un itinerario madurativo genéticamente preestablecido. Respecto de esta visión nos encontraremos adentro y afuera, al abordar lo que desde la institucionalidad del SENAME y el aparato jurídico comprende por infancia en el sentido temporal; no obstante buscaremos ir más allá de ella al relacionarla con la concepción filosófica que Agamben (2003) desarrolla sobre la infancia. A continuación abordaré más en detalle esta cuestión. En este sentido, la concepción de Agamben sobre la infancia trasciende una edad determinada adscrita al desarrollo biológico madurativo, siendo para él lo que hay de previo al lenguaje para el viviente humano, un no-lugar del lenguaje, que por ello hace posible la experiencia particular.

Desde la concepción agambeniana, este desmarcar a la infancia con el modelo desarrollista implica un punto de ruptura de manera directa con la perspectiva reduccionistamente biologicista promovida por lo que se puede concebir como discurso biomédico dentro de las ciencias naturales. De manera indirecta se promoverá repensar la naturaleza intrínsecamente lingüística del ser humano presentada como una "dictadura" del lenguaje desde la filosofía del lenguaje y con el constructivismo y construccionismo, desde las ciencias sociales. Lo relevante de esta demarcación radica en la posibilidad rescatar la potencia de lo vivo desde mecanismos epistemológicos de captura que 
reducen su complejidad en un determinismo en uno u otro sentido, biológico o lingüístico, exiliando la posibilidad de lo inefable que la experiencia en sí misma presenta. Esta es la propuesta para ir desde un primado de lo simbólico hacia la apertura hacia lo real, en palabras de Lacan (Dor, 1994), es decir, de concebir lo humano dentro de una estructura lingüística cultural que define a priori la posición del sujeto en una serie de intercambios significantes, hacia una posición abierta a lo contradictorio y lo no simbolizable de la experiencia a través del lenguaje. En este sentido es que dicha potencia de lo vivo que expresa la infancia radica en el hecho fundamental de diferenciar lo humano del lenguaje, concibiendo éste ya no como una estructura que sobredetermina y que por ello empobrece el estatuto de la existencia, donde el hombre ya no sería sólo un zoón logon, un animal racional desde un comienzo, sino más bien con la posibilidad de adquirir y apropiarse de un lenguaje por medio de la experiencia. Así, la experiencia como la infancia del hombre, la que lo libera de la determinación al lenguaje, establece la radical “...diferencia entre lo humano y lo lingüístico...que el hombre no sea desde siempre hablante, que haya sido y sea todavía in-fante, eso es la experiencia" (Agamben, 2004, p. 70). Ello impone una dinámica existencial compleja, por así decirlo, entre el viviente y el lenguaje, dinámica donde la experiencia "instaura efectivamente en el lenguaje la escisión entre lengua y discurso que caracteriza la manera exclusiva y fundamental al lenguaje del hombre."(Ibid., p. 71). Esta escisión corresponde a la diferencia entre lo semiótico y lo semántico, donde sólo la apropiación del signo por el viviente permite su enunciación. Esta dialéctica da cuenta de la particularidad del ser humano, quien no solamente expresa o es un vector de una cadena significante, sino más bien, es coherente, está comprometido con lo real propio que lo define en su existencia única y que se comporta como una verdad que va más allá de las palabras. Ese real que comporta la experiencia de lo humano sería homologable al ello de Freud (2006), a lo inconsciente, como aquello que no tiene ni tendrá acceso a la consciencia ni a la representación y que funda la operación del ser sujeto en una cultura, da cabida a la subjetividad de lo propio. Así podemos entender a la infancia como un espacio psíquico con la cualidad de ser un vacío fundante, cuya falta moviliza a una confrontación del sujeto en su doble vertiente: como animal mudo y como racional parlanchín. Por ello el hombre, "en tanto que tiene una infancia, en tanto que no es hablante desde siempre, escinde esa lengua una y se sitúa como aquel que para hablar, debe constituirse como sujeto del lenguaje, debe decir yo" (Agamben, 2003, p. 72) Eso es la infancia. La posibilidad de apropiarse de los signos para que haya una enunciación detrás de la cual está el sujeto, que, por conservar su infancia, puede hablar de sí como viviente. Y además, sólo por eso, por devenir de una fractura entre un lugar preestablecido para su existencia y algo propio pero irrepresentable, es que el viviente humano puede ser un ser en potencia, y puede devenir histórico.

En este cuadro de situaciones, teniendo un viviente no desde siempre ligado al lenguaje, sino con posibilidades de apropiárselo y siempre con un resto de infancia ligada a una experiencia, irrepresentable y asociada a la propia verdad siempre en busca de inscripción en el lenguaje, es que existe el lugar para la existencia particular, para la creación. Para resolver eso particular que urge y empuja en una matriz existente previamente pero que no se cesa de escribir en la historia. Ahora, en otro orden de cosas, dicha infancia será, para el objeto de la presente reflexión, lo cual posibilita la irrupción de lo excluido en una sociedad, en un discurso dominante. Con ello comparto la idea de Foucault de que

“...en toda sociedad la producción del discurso está a la vez controlada, seleccionada y redistribuida por cierto número de procedimientos que tienen por función conjurar sus poderes y peligros, dominar el acontecimiento aleatorio y esquivar su pesada y temible materialidad.”(Foucault, 1996, p.14).

Dichos modos serán abordados más adelante.

En particular la infancia se nos presenta en la niñez y la adolescencia (aunque más perdurable en uno que otro "grande" o adulto), como una experiencia fundamentalmente abierta, con un mayor ímpetu dado el carácter de potencia que tienen dichas edades, así como por el hecho de que son niños y jóvenes quienes resienten y espejean lo que el orden del mundo adulto, desde ya heterogéneo y con sus propias exclusiones, le brinda o no a su llegada a la cultura y la historia como vivientes. 
La infancia se nos presenta así como una experiencia donde los sujetos aún no se encuentran completamente adscritos a ese orden social tan natural al mundo adulto y trasmitido por su lenguaje, su discurso. Ello la convierte en un resto necesario de la operación de formación de los sujetos, pero a la vez peligroso para el discurso hegemónico pues puede devenir como una retaliación desde fuera a desarmarlo y cuestionar sus dispositivos de control. Por esto se hace necesario capturarla, incluyéndola pero a la vez excluyéndola, controlándola para que no emerja a modo de la fuerza negativa del gran rechazo que hablaría Marcuse (1985), como una negación sobre lo positivo y manifiesto de discurso y acción social..

Dentro de esta perspectiva es que también cabe pensar en la dimensión biopolítica del control de la infancia, no de la niñez, sino de la infancia como potencia. El hecho que el lenguaje ejerza una violencia sin precedentes en la propia carne del viviente, que excluya parte de ella para que le sea permitido acceder al estatuto de sujeto, y que a la vez sea éste mismo reproduzca dicha operación sin cesar, implica la intrusión del orden de un discurso en lo suyo más propio y material, más visceral. De la misma manera que la infancia busca la apropiación subjetiva, el lenguaje compartido introduce lo compartido, lo cultural, pero ello no es nada de neutro. Desde dicha operación anatomopolítica de la carne se despliega el polo hacia una biopolítica de la población seriada y estandarizada bajo la distribución normal: todos bajo los mismos parámetros, todos biológicamente programados de la misma manera para los mismos fines predeterminados. Eso es la destrucción de la experiencia agambeniana de la infancia, la aniquilación de lo más enigmático e inefable de la experiencia para traducirlo en lo más común y trivial, donde la experiencia trascendental del zen matutino se homologa a las dos horas de gimnasio diarios o a una saludable dieta para evitar la oxidación celular en una cultura de consumo. La reducción de la infancia como peligro para el discurso hegemónico, llevada a cabo mediante diversos dispositivos de captura, es homologable a la transformación de lo que los griegos denominaban bios y que denotaba una vida cualitativamente diferenciada e inscrita en el interior de la polis (política), hacia la zoé, una vida desnuda y desprovista de cualquier subjetividad. Y justamente en esta operación de captura y exclusión de la infancia, mediada por el lenguaje, es donde el sujeto en tanto viviente articulado a éste, es reducido a una vida desnuda, un cuerpo biológico desprovisto de cualquier particularidad y que por ende es posible de homologar a otros como él a la manera de individuos estadísticamente agrupados. Esta zoé como una “... simple vida natural es excluida del ámbito de la polis en sentido propio y queda confinada en exclusiva, como mera vida reproductiva, en el ámbito de la oikos"(Agamben, 2003 ; p. 10). La vida reducida a los cálculos económicos y domésticos, no contemplada desde la dimensión política que el viviente se ha adjudicado mediante la experiencia de su infancia.

Esta vida desnuda será “... a quien cualquiera puede dar muerte pero que es a la vez insacrificable del homo sacer...en que la vida humana se incluye en el orden jurídico únicamente bajo la forma de su exclusión" (Ibid, p. 18), es decir, quedando vulnerable por el hecho de ser protegida y venerada. A propósito del tema de este escrito, como se verá más adelante, ello dice relación con el imperativo moral cuasi teológico de defender la infancia a toda costa, donde la Convención de los Derechos de los Niños aparece como los diez mandamientos o mas bien como el código de Hamurabi., y su jurisdicción llega a mutilarla con el aparato psicosociojurídico empleado aporéticamente con el fin de preservarla, de defender sus derechos. Allí es, dentro del marco de una soberanía política donde se anuda el control del Estado a estas políticas de subjtivación en la carne y en el cuerpo, como verdaderas tecnologías del yo que apresan lo particular, lo real de la infancia, (y he ahí la aporía) desde allí actúan como biopoder. Así la vida desnuda queda fuera de la polis pero a la vez apresada por los mecanismos de control “...en tal fractura en la forma de excepción, es decir de algo que sólo es incluido por medio de una exclusión.”(Ibid., p 21). La excepción consiste en que el Estado, para defender al homo sacer y su sagrada vida biológica, dispone de matarlo en cualquier momento de ser necesario para la preservación de ésta como un imperativo categórico.

En este sentido que la Infancia de la infancia o niñez del hombre trata de ser capturada sin cesar por dispositivos biopolíticos para ser despolitizada, llevada de la bios a la zoé, y con ello ser administrada desde el anonimato de la cifra estadística y del cuerpo biológico seriado, y conjurar el peligro de irrupción que expresa para la máquina gubernamental, cual fantasma que amenaza con volver 
del exilio y del silencio. La Infancia y la infancia se encuentran en estado de excepción, se preservan y defienden a toda costa, de la misma manera que se atormentan y hostilizan sin cesar.

\section{Para una breve arqueología de la infancia en Chile}

Con el propósito de referirme a la política institucional de la infancia que sostiene el SENAME, me parece pertinente introducir la dimensión histórica del problema, o mejor dicho, una breve arqueología, que permita apreciar su derrotero longitudinal y con ello su prehistoria. Gabriel Salazar (1989) en su texto Ser niño "huacho" en la historia de Chile realiza un recorrido historiográfico por la historia "no oficial" de la infancia, la niñez, de los incipientes estratos populares del siglo XIX-XX, donde plantea sus principales avatares y conflictos. He ahí expuesta la dificultad para la infancia, la falta del padre y la figura de una madre agobiada por sus responsabilidades, por el peso de un deber de criar, y en dónde los niños proliferaban por doquier, situación que ponía en apuros al orden público . Frente a ello las autoridades de la época reaccionaban de forma punitiva y excluyente, escandalizadas con los juegos de los niños, las bandas, y una sexualidad "pecaminosa” percibida en las clases populares donde éstos pertenecían. Plantea Salazar,

"La verdad fue siempre que ¡sobrábamos! Había que comprenderlo: para nosotros la vida no consistía en seguir majaderamente las huellas de papá y mamá. No podíamos repetir el ejemplo que nos daban. No tenía sentido construir nada puertas adentro. No con ellos. No allí dentro. Nuestra única posibilidad radicaba en buscarnos entre nosotros mismos puertas afuera. En construir algo entre los "huachos" y para los "huachos". Estaba claro. Teníamos que apandillarnos o morir” (Salazar, 1989, p. 9-10).

De esta forma, las condiciones difíciles para la infancia, la falta de sostén paterno y la pobreza, generaban un clima propicio y necesario para que los niños formaran grupos encontrando en éstos el único sostén y referente con que mantenerse vivos. Esta situación era la que se escapaba de las manos a las autoridades de la joven nación del "por la razón o la fuerza”, haciendo uso de la fuerza que el orden jurídico y policial le entregaba, decretando ordenanzas como las siguientes:

Artículo 2: Es prohibido en las calles, plazas u otros sitios públicos, juegos de bolos, ruedas de fortuna, naipes, dados, chapas, trompo de clavar, taba, volantín i demás semejantes, bajo la pena de 4 a 8 días de presidio a cada uno de los que estuviesen, bien sea jugando o aciendo parte de la reunión en que se juega. [AMI, Vol., 203, 8 de enero de 1847. Reglamento de policía de Valparaíso]

Artículo 65: Todo niño que se encontrare jugando o cometiendo desórdenes en las calles será conducido por 24 horas al cuartel de policía, pudiendo sus padres rescatarlos pagando una multa de 25 centavos. Los que no paguen las multas...sufrirán una prisión de 24 horas por cada 25 centavos. [AMI, Vol. 98, 25 de septiembre de 1874. Ordenanza de Policía de Los Angeles] (Ibid., p. 12-13)

Estas medidas, de manera explícita, surgen frente al temor a que las calles se transformen en un patio de juegos, y que ello devenga un lugar de cultivo de la delincuencia, la prostitución y la inmoralidad. Es decir, que irrumpan prácticas opuestas a la de la clase hegemónica, frente a su discurso y sus intereses. Esta represión al jugar será una represión a la infancia, al intento de crear y de apropiarse algo de lugar en una situación donde no les ha sido asignado ninguno para existir. Ese es el mundo del huacho y las contradicciones del orden social que anuncia con su existencia.

Pero también surgirán instituciones con fines humanitarios, como la Casa de expósitos para recepción de huérfanos, encargadas a religiosas católicas, para que se pueda hacer vivir la sagrada vida que Dios nos ha regalado con los pequeños abandonados, de los cuales nada se esperará y que con mucha suerte llegarán a ser un buen ciudadano, un aporte a la sociedad.

En este sentido ya podemos ir apreciando dos cosas: una es la precariedad y las dificultades de la infancia en el primer tiempo de Chile, marcado por la pobreza pero con una buena dosis de abandono; lo segundo es que desde ya se aplicaba el rigor de la ley para evitar que niños cometieran disturbios ni implicaran ningún tipo de peligro para las autoridades. En un nivel de lectura más pro- 
fundo, se puede pensar que esta infancia, estos niños, venían a irrumpir en la construcción del orden de una nación emergente, y de una u otra forma explicitaban otro orden, otra versión de la realidad, otro discurso que venía a mostrar las problemáticas sociales de la época. A estos niños peligrosos, tratados como delincuentes, se les aplicaba todo el rigor de la ley y se les capturaba en un dispositivo jurídico-asistencial destinado a tenerlos entre a beneficencia y el castigo, la protección y la exclusión. Desde ya las políticas gubernamentales para niños y adolescentes, sobre todo de extracción social popular, estarían destinadas a esta suerte, en la mayoría de los casos el castigo y el rechazo social, y en el menor, considerando que aún no se refinaban los métodos de control que derivarían de las ciencias sociales de mitades del siglo XX, al abrigo de una institución que reforme y discipline.

Es en este contexto nacional, con una trayectoria histórico-institucional particular, que años más tarde, y derivado de la escena internacional post segunda guerra, aparecen los Derechos de los Niños como resabio casi natural de los derechos humanos. En este devenir es que las instituciones disciplinatorias para los niños y jóvenes van a ir evolucionando hacia versiones más hermoseadas y coherentes con los discursos políticamente correctos y cuasi teológicos de los derechos humanos derivados de la ONU.

Dentro de esta coyuntura va a aparecer SENAME, en el primer periodo de la dictadura militar, creado por el Decreto Ley N 2.465 del 10 de enero de 1979, publicada en el Diario Oficial el 16 de enero de dicho año, siendo establecido como un ente derivado del Ministerio de Justicia encargado de administrar la problemática de los “menores” de edad. Será más adelante, en la vuelta a la democracia, que este organismo tomará otro cariz, con la bandera del progresismo y tras el reconocimiento de la Convención de los Derechos del Niño.

\section{SENAME, lo proteccional y lo infraccional. Entre la horrible tarea de castigar y el hermoso oficio de curar.}

En esta parte del escrito, ya habiendo abordado las conceptualizaciones referidas a la infancia y su captura, la vida desnuda y el estado de excepción, así como una breve referencia a la situación de la infancia en Chile y las medidas utilizadas por las autoridades respecto de sus problemáticas, sólo resta abordar en detalle la institucionalidad del SENAME a través de su Marco General. Primero que nada, y extendiéndome algo en el punto anterior, cabe mencionar que esta institución dependiente del Ministerio de Justicia de Chile en lo particular se encuentra entrelazada con el accionar de los tribunales de familia sobre los casos de niños que se encuentran "judicializados", articulándose como un brazo operacionalmente orientado la intervención y la práctica de las resoluciones emanadas de ésta, así como Carabineros e Investigaciones cumplen asimismo otro rol, y cuya égida es promover e imponer el cumplimiento de la declaración internacional de los Derechos de los Niños. Ya este dato significativo, de administrar la justicia a los “menores” de edad (o ayudar en ello), toma otras aristas cuando se incorpora el último cambio en la materia, a saber, la promulgación de Ley de Responsabilidad Penal Juvenil.

Desde 1990 hacia la fecha, señala el texto, que SENAME ha pasado por "un proceso gradual de cambio desde una óptica y prácticas "asistencialistas", fundadas en la "situación irregular de la infancia”, en dirección a una óptica y prácticas de protección integral, fundadas en la Convención Internacional sobre los Derechos del Niño" (SENAME, p. 4). Ello comienza con "Las Nuevas Políticas del Servicio Nacional de Menores", seguida muy posteriormente en el 2001 por la "Política Nacional y Plan de Acción Integrado en favor de la Infancia y la Adolescencia”. En este proceso se esbozan cambios respecto al enfoque y la "oferta programática”, disminuyendo programas residenciales y aumentando los ambulatorios, centrándose estos últimos en dos áreas: la prevención de la vulneración de derechos y la reparación (referida a problemáticas como consumo de drogas, maltrato, niños/as de y en la calle, trabajo infantil, explotación sexual e inimputables), dónde ya se hace énfasis en lo diagnóstico como algo solicitado frecuentemente por Tribunales y Fiscalías. Además de ello se hace explícito el hacerse cargo de la temática de los adolescentes infractores de ley, en el marco de la mencionada ley de responsabilidad penal adolescente. A propósito de ésta política es que se manifiesta como algo necesario el "distinguir, pero también establecer, las relaciones existentes en como se aborda lo "proteccional propiamente tal" y lo "infraccional”(Ibid., p. 6), es decir, la 
articulación entre 1 la protección de los derechos de infancia, y lo referido a administrar las condenas a adolescentes que hayan cometido delitos. Lo interesante de ello es la manera en cómo se propone la administración de las penas, lo infraccional, como siendo algo coherente con la Convención Internacional sobre de los Derechos del niño, en tanto también formaría parte de una tarea educativa, formativa para el adolescente. No obstante, tras esta diferenciación se rearticulan ambas esferas, al

“explicitar que en un Estado de derecho la política criminal hacia menores de edad sólo puede ser tributaria de una política social de protección integral de derechos. ... a los adolescentes infractores de la ley penal se le deben garantizar sus derechos, como lo es con toda la infancia y adolescencia del país.” (Ibid., p. 6)

Esta distinción y rearticulación es vuelta a afirmar cómo aporía entre dos campos excluyentes pero mutuamente necesarios, donde "es importante no confundir ambas situaciones: protección y sanción, aún cuando en ocasiones ambas se presenten en la vida del/a mismo/a adolescente" (Ibid., p. 7). Si leemos entre líneas esto quiere decir que se considera como un hecho que ambas políticas vayan orientadas hacia un sujeto que se ve "desprotegido", vulnerado a propósito de sus derechos, situación de vida potencialmente asociada al transformarse en un riesgo para la sociedad, razón por la cual debe ser educado. Con ello se va configurando el perfil del joven marginal, un excluido social. Indagaré de qué manera esta figura se va formando a través de estos lineamientos, en la manera cómo se van entrecruzando la difícil tarea de castigar y la hermosa tarea de curar, en este caso proteger y/o rehabilitar. Podemos pensar que este niño y adolescente es el derivado histórico de la figura del huacho de la que nos habla Salazar, y contraponer las medidas desarrolladas previamente para su control, en el siglo pasado, frente a esta máquina aporística y a este niño-joven vulnerado. Me parece evidente que en este discurso se trata de un niño huacho, sin padre ni madre, encargado al leviatán del Estado, en tanto está desprotegido y es pasado a llevar en sus derechos sin nadie que lo ampare, y también carenciado socioeconómicamente. De ello ser deriva la conclusión implícita, operación automática de pensar que en cualquier momento este sujeto puede incurrir en la delincuencia.

Volviendo al texto de SENAME, en él aparece una función rectificadora, normalizadora para este menor doblemente desviado, a la vez víctima y victimario, de buscar su inserción social y laboral. No es que necesariamente todo niño dentro de SENAME será delincuente a la vez que abusado. Más que nada se trata de señalar de qué manera el niño doblemente desviado, sin protección y sin ley, constituye el paradigma, como caso singular que remite a otros singulares, de la acción de la institución hacia la población infanto-juvenil, y con ello devela su verdad última, a saber, de servir como un dispositivo de control para los niños potencialmente peligrosos así como para los adolescentes que ya lo son dada su situación de "vulneración”. Ello se iría desplegando como un biopoder, en tanto se desnuda la infancia como algo manipulable y por lo tanto estabilizable dentro de ciertos cánones sociales para que no devenga problemática. Justamente es ello reducirla a una vida desnuda, desactivar su in-fancia como posibilidad de apropiarse algo del orden de lo propio a través del lenguaje, en un contexto social donde falta el lugar para ellos. El niño-joven marginal no puede apropiarse de nada, no tiene derecho para nada salvo para seguir las normas, y de ello deriva que termina apropiándose de lo material en un fuera-de-la-ley. Y como una profecía autocumplida, se convierte en delincuente.

Esta máquina, este dispositivo y la manera en que estos dos paradigmas se articulan en esta aporía queda expresada en la misión para los años 2006-2010:

“Liderar, promover y fortalecer un Sistema Nacional de Protección de los derechos de niños, niñas y adolescentes vulnerados y de responsabilización de los infractores de ley, a través de programas integrales de atención que permitan una oportuna restitución y reinserción social, con un enfoque intersectorial, territorial y de calidad” (Ibid., p. 8)

Dicha articulación ya es bien enunciada por Foucault, quien señala a propósito de la pericia psicológica, utilizada como conexión entre el discurso médico-psiquiátrico y el judicial, que “...la sociedad va a responder a la criminalidad patológica de dos modos, o más bien va a proponer una respuesta homogénea con dos polos: uno, expiatorio; el otro, terapéutico.” (Foucault, 2006, p. 41). 
De manera similar ocurre con la protección de los derechos, por un lado, y la infracción, por otro, donde cabe preguntarse “...todo este continuum, que tiene su polo terapéutico y su polo judicial, toda esta mixtura institucional, ¿̇a qué responde? Pues bien, al peligro.” (Ibid., p. 41)

¿Al peligro de qué? De lo que genera para el orden público, o lo que potencialmente puede generar su situación de exclusión, donde la vulneración actúa como pasaporte seguro al otro extremo aporético, la delincuencia. Respecto de dicho término, vulneración, éste aparece asociado a los niños y adolescentes "especialmente si están viviendo en condiciones de pobreza o en situaciones de baja complejidad relativas a la vulnerabilidad de sus derechos” (Ibid., p. 10), los excluidos del sistema económico que a la vez se incluyen en un aparato de captura para ejercer el control sobre su potencial peligrosidad. En este contexto se efectúa una intromisión al hogar, la familia y el propio cuerpo del niño, situación que refiere una vigilancia directa sobre una vida que ha devenido sagrada, o más bien una infancia sagrada, que puede ser mutilada en cualquier momento para ser preservada. Para este "niño sacer" se ha destinado

...la existencia de tribunales especiales, los tribunales de menores, en los cuales la información de que está encargado el juez, que es a la vez el de la instrucción y el del juicio, es esencialmente psicológica, social, médica... se refiere mucho más al contexto de existencia, de vida, de disciplina del individuo, que el acto mismo que ha cometido. (Ibid., p. 46)

Se propone necesaria esta intrusión en el bios subjetivo del niño y su familia, transformándolo en un zoé, operación de descualificación de una vida política efectuada con el objeto de estar atento que su propia vulnerabilidad no se transforme en un peligro para la sociedad. Dentro de ello están las prácticas de quitar los hijos a sus padres, de actuar cuasi policíacamente en visitas domiciliarias con el objeto de pesquisar la norma o su infracción en niños y adolescentes desviados, así como en sus propias familias y hogares.

La variable "vulneración” fue operacionalizada demarcando tres tipos de complejidad, derivadas de la magnitud de desviación que el niño y su contexto presentan con respecto de lo que se espera de la infancia

"Nivel de Baja Complejidad: Presencia de situaciones y/o conductas que se constituyen en señales de alerta para considerar, pero que no provocan un daño evidente en niños/as y adolescentes en lo que al ejercicio de sus derechos se refiere. Nivel de Mediana Complejidad: Presencia de situaciones y/o conductas que se constituyen en evidentes señales de alerta, que provocan daño y/o amenazan los derechos de niños/as y adolescentes.

Nivel de Alta Complejidad: Presencia de situaciones y/o conductas que provocan un grave daño a la integridad física y/o psicológica de niños/as y adolescentes.” (Ibid, p. 10)

A partir del nivel de vulneración manifiesto es que se diseñan estrategias para administrar los cuerpos de la infancia, derivándolos a los consiguientes programas, como vidas desnudas que requieren una readecuación para adaptarse e insertarse en el mundo feliz que les tiene preparado el discurso dominante, del cual ellos son fiel reflejo de su contradicción inmanente, de su imposibilidad de alcanzarlo. Descualificándolos como zoé, en tanto no importa tanto quienes son ni cómo las problemáticas de vida e asocian a su subjetividad, sino la manera de cómo se complejiza su vulneración a ojos de un ente administrador. El Estado de Chile, SENAME. Con este tipo de lineamientos muchas veces va a primar el encauzamiento del niño a la norma, la máxima de que sean respetados sus derechos más que de rescatar o proponer la construcción para una verdad propia a sí mismo como sujeto con historia e Infancia. Así, es adosada al nivel de vulneración el riesgo, el potencial peligro que el niño tendrá consigo mismo y hacia la sociedad. En el segundo y tercer nivel se rearticulan y de desdibujan las diferencias antes enunciadas entre lo proteccional y lo infraccional respecto de: 


\begin{abstract}
“situaciones de pre-deserción escolar, consumo aún no problemático de drogas, conductas trasgresoras que no llegan a tipificarse de delito, vínculos intrafamiliares basados en relaciones sostenidas de violencia, instalados en un contexto marcado por lo infraccional (violencia, tráfico, etc.) en sus relaciones de pares...”
\end{abstract}

$\mathrm{y}$

“...deserción escolar prolongada, consumo problemático de drogas, peores formas de trabajo infantil, explotación sexual comercial, conductas trasgresoras tipificadas como delito, familias ausentes o con conductas altamente negligentes, vínculos familiares altamente violentos, viviendo en caletas, con requerimiento de separación de su núcleo familiar de origen, etc.” (Ibid, p.;12)

Como efecto halo y producto de la metonimia, tanto vulneración como infracción son parte del mismo conjunto; efecto de sentido de estigmatizar la pobreza para poder administrarla de manera mas eficaz. Ello con respecto a una noción de riesgo que se adscribirá "de preferencia en sectores caracterizados por la desigualdad de condiciones y de expectativas de vida” (Ibid., p. 12), es decir, como se había señalado previamente, delineando una situación de exclusión. Dicha perspectiva se plasmará en un enfoque territorial, que estandariza los sectores geográficos de la urbe que presenten más vulnerabilidad en sus condiciones sociales, culturales y económicas, a la manera que Foucault describe a propósito del circunscribir un territorio cerrado para controlar las anomalías de la población pero sin excluirla de la polis. Enfoque territorial que implica realizar una "individualización, por consiguiente, división y subdivisión del poder, que llega hasta coincidir con el grano fino de la individualidad" (Foucault, 2006, p. 53). Se trata de un constante escrutinio del cuerpo individual, en el colegio, en el hogar, mediante una red de informantes clave dispuestos a señalar si el niño o su familia se han desviado de la norma, del mandamiento del derecho del niño.

Aquí no se trata de ir en contra de los derechos de infancia, sino más bien develar la calidad de excepción que se articula en ellos respecto de el cuerpo, físico o psíquico de un niño, y cómo puede ser aún más vulnerado por el poder soberano al llegar a violentar su espacio vital con el ideal de cumplir la norma.

Para ir finalizando quisiera citar un pasaje referido al estatuto de la acción del profesional con niños vulnerados en sus derechos, donde la intervención social, educativa y/o psicológica se expresa como cuidados y asistencia especiales necesarios "particularmente cuando esta voluntad y búsqueda han sido dañadas, afectadas, menoscabadas o, sencillamente, no consideradas, reduciéndolo/a a una condición de objeto" (SENAME.; p. 18). A lo que hace alusión esta cita es a una voluntad de corte humanista de crecimiento personal y de autoactualización, que el niño o adolescente ha perdido producto de su vulneración. No obstante cabe plantearse la objeción a modo de pregunta: ¿no es la misma condición de objeto que se describe como producto de la vulneración de derechos, a la que es reducido el niño por el poder soberano, el sistema judicial, mediante su regla de excepción, de poder administrar su ser como viviente deviniendo entonces una vida desnuda sólo con el objeto de cumplir la norma? Me quedo con esta pregunta a modo escansión y cierre.

\title{
Conclusiones. De la infancia hacia la vida desnuda, exclusión inclusiva.
}

Referido a la problemática de la infancia, como etapa del desarrollo, es que se ha abordado el quehacer de la institución del SENAME como máquina que expresa la aporía entre dos polos antitéticos pero dependientes: lo proteccional y lo infraccional, como ámbitos de las políticas de infancia en Chile. Esta sería una articulación que tendría su ámbito de acción en la "prevención” de la vulneración en niños y adolescentes, como polo referido al arte de curar, pero sin embargo encontraría su verdadera naturaleza, adscrita al sistema jurídico en los adolescentes infractores de ley, que constituirían su paradigma. Ello develaría su polo oculto y silencioso, el arte de castigar que se esboza como derrotero de una política normalizadora, en un discurso hegemónico respecto de lo social. En ello está silenciada la pregunta acerca de las condiciones socioeconómicas y de injusticia que están 
a la base de la producción de sujetos carenciados, que se encubren bajo una extraña atribución causal a deficiencias del medio social (territorios de riesgo), la familia (padres maltratadores o negligentes), y de los efectos de la vulneración en el niño. Pero nada se dice de ello que éste espeja respecto del orden establecido en el que por primera vez fue excluido y ahora es incluido, a propósito de conjurar la terrible materialidad que implicaría una irrupción en el orden establecido, un orden que nada quiere saber de aquello que desecha y niega.

Esta política tiene un devenir histórico, o más bien una prehistoria, compartida con la exclusión que era objeto el niño huacho de Salazar, que debía apandillarse o morir; se trata de una política social punitiva y una represión constante por el hecho de buscar un lugar en el mundo habiendo sido arrojado a él sin uno merecido por derecho propio. Respecto a esta prehistoria me parece que el SENAME responde, continuando la labor normalizadora y punitiva heredada del modelo establecido de antaño, pero con herramientas más eficaces y bajo la ascéptica mirada de la convención de los derechos de la infancia y su teología del niño sagrado (que probablemente se emparenta con la devoción hacia el niño Jesús). Entonces, no hay nada nuevo en la declaración de cambio de enfoque, salvo el medio para cumplir los fines de disciplinamiento. La niñez y adolescencia excluida en Chile lo sigue siendo día a día, y su real voz, su yo como enunciante, se ve coartado. Ello mediante una eficaz administración de las problemáticas estratificada en tres niveles de complejidad, según la vulneración de derecho, y que deriva en una descualificación de los vivientes para transformarlos, desnudarlos y administrarlos correctamente en una intrusión institucional de lo público en lo privado sin límites y sin precedentes. Aquella vida desnuda del homo sacer que puede ser sacrificada con el propósito de mantenerla con vida; niños separados de sus padres para que los tribunales definan quiénes podrán desempeñar adecuadamente ese rol, pero sin mediar la necesidad propia del niño como sujeto. Sin psiquis ni palabra. Sólo un ente amorfo y manipulable, desprovisto de toda subjetividad.

Entonces ¿Qué es lo que el SENAME busca conjurar? ¿Qué es aquello que se teme y se considera riesgo? En un más allá de la vulneración, que el niño sea maltratado; más allá de la infracción de ley, el joven delincuente desviado; se conjura la posibilidad que la infancia aparezca, en el sentido de la infancia de la experiencia, como una potencia que sobrevenga a la exclusión por la que es objeto al ser convertida en una vida desnuda, y retorne tal como lo forcluido del psicótico, en un juego de poder que venga a cuestionar y modificar el orden establecido del discurso dominante. En este sentido, la infancia del niño, joven y adulto le es peligrosa al Estado soberano en su búsqueda de control de los cuerpos y subjetividades. Y en tanto por ello se entiende el porqué de la peligrosidad de la infancia en Chile, como nación frágil imposibilitada de hablar de sus orígenes, de sus deudas históricas que aparecen e intentan reescribirse en éstos detentores de la infancia. Así se establece una signatura respecto de lo dicho y lo que no puede decirse, lo que no tiene espacio para ser hablado y que se busca dar caza constantemente mediante una máquina encarnativa ${ }^{2}$ que transforma la carne en cuerpos delimitados para su utilización. La infancia es la carne, que puja por volver, como lo reprimido insiste en retornar a la consciencia para hablar de un pasado originario ya olvidado, y mediante ello remodelar los cuerpos controlados por el discurso en su zoé.

En este dispositivo, en una constante vuelta hacia lo mismo, lo judicial busca ligar lo viviente al dogma, a los códigos que, como el lenguaje, preceden su existencia. La infancia en este sentido es problemática para la justicia porque socava sus bases refiriéndola constantemente a la experiencia desdogmatizando su poder. Por ello habría que atraparla, capturarla. Donde la ley es pura palabrería, la infancia es un espacio de un no-espacio del habla, al cual el discurso médico jurídico atrapar signándolo en un no-respeto, con una aplastante dictadura epistemológica, primado de la razón. Pero no es una razón neutra, sino un discurso de poder.

En este cuadro ¿̇Se podrá instituir en una sociedad, gobierno o modelo político un no-lugar para el habla, un espacio para la infancia, para lo inabarcable del ser humano? ¿Se puede pensar en una institución para la niñez que respete su in-fancia y su particularidad?

2 Expresión acuñada por el filósofo R. Karmy para su tesis doctoral 


\section{Referencias}

Agamben, G. (2003). El Homo sacer. El poder soberano y la nuda vida (1ª ed.). Valencia: Pretextos.

Agamben, G. (2004). Infancia e historia: destrucción de la experiencia y origen de la historia ( $1^{\text {a }}$ ed.). Buenos Aires: Adriana Hidalgo editora.

Freud, S. (2006). Obras completas: El yo y el ello y otras obras ( $2^{\mathrm{a}}$ ed.,10 $10^{\mathrm{a}}$ reimp.). Buenos Aires: Amorrortu.

Foucault, M. (1996). El orden del discurso (1 $1^{\mathrm{a}}$ ed.). Madrid: Ediciones Endymión.

Foucault, M. (2006). Los anormales ( $2^{\text {a }}$ reimpresión) Ciudad de México: Fondo de cultura económica.

Dor, J. (1994). Introducción a la lectura de Lacan I: El inconsciente estructurado como lenguaje (1 ${ }^{\mathrm{a}}$ ed.). Barcelona: Gedisa.

Marcuse, H. (1985). El Hombre unidimensional. (1 $1^{\mathrm{a}}$ ed.). Barcelona: Editorial Planeta-De Agostini.

Salazar, G. (1989). Ser niño huacho en la historia de Chile. Recuperado el 19 de Julio de 2009, desde la página

http://www.archivochile.com/Ideas_Autores/salazarvg/salazarvg0003.pdf.

SENAME. La acción del Servicio Nacional de Menores en el ámbito de protección de derechos de la infancia y adolescencia. Recuperado el 15 de Mayo de 2009, desde la página

http://www.sename.cl/wsename/otros/doc_sename/marco_general_2006-2010.doc 